\title{
¿Consumidores o ciudadanos? Prácticas de consumo cultural de los inmigrantes latinoamericanos en España
}

\section{Consumers or citizens? Practices of cultural consumption of Latin American immigrants in Spain}

Jéssica Retis ${ }^{1}$

Resumen: El presente trabajo ${ }^{2}$ analiza el fenómeno migratorio de la población latinoamericana en Europa, específicamente en España, centrando su atención en las dinámicas y los rasgos que caracterizan el consumo comunicacional y cultural que esta población, en tanto diáspora, efectúa en su nuevo contexto vivencial, marcado por el vínculo entre lo local y lo global.

Palabras clave: Migración; Población Latinoamericana; España; Consumo Comunicacional y Cultural

Abstract: This paper analyzes cultural practices of Latin American immigrants in Spain. Based on surveys and in-depth interviews, it analyzes dynamics and characteristics of communication and cultural consumption, diasporic practices and intersections between local and global synergies on transnational contexts.

Keyword: Migration; Latin Americans; Spain; Communication and Cultural Consumption

1 California State University Northridge. Los Angeles, Califórnia, Estados Unidos. E-mail: jessica.retis@gmail.com

2 Este texto es parte de una investigación más amplia publicada en el documento de trabajo Estudio exploratorio sobre el consumo cultural de los inmigrantes latinoamericanos en España: el contexto transnacional de las prácticas culturales, Madrid: Fundación Alternativas. 


\section{Introducción}

Los desplazamientos de población desde América Latina hacia España han sido constantes a lo largo de la segunda mitad del siglo pasado y hasta nuestros días. Sin embargo, el incremento acumulado de migraciones económicas provenientes especialmente de Sudamérica empezó a ser significativo a partir de mediados de los ochenta, cuando los flujos económicos superaron a los provenientes de los exilios políticos. Fueron principalmente peruanos y dominicanos quienes se incorporaron a los «nichos laborales» abiertos en las «ciudades globales» (SASSEN, 2001) de Madrid y Barcelona: sectores de cuidados de ancianos y niños, servicios y hostelería. La última mitad de los años noventa, pero particularmente el cambio de siglo, trajeron consigo los efectos de las políticas de reajuste estructural del modelo neoliberal en las crisis económicas y financieras sudamericanas, mientras que se asentaba la bonanza económica en España. Las sinergias de expulsión de flujos migratorios desde América Latina y de atracción de flujos en Europa se conjugaron con las reformas del contexto migratorio hacia Estados Unidos, principal país atrayente de flujos latinoamericanos, produciéndose una reconfiguración de los desplazamientos. Las crisis financieras en Ecuador, Colombia y Argentina, particularmente, se compaginaron geopolíticamente con un mercado laboral que se abrió a la mano de obra extranjera en España. Los migrantes siguieron la estela de los flujos de capital internacional extranjero, pero en sentido contrario: la «década dorada» de las inversiones españolas en América Latina (CASILDA, 2002) se compaginó con los procesos de salida de las clases medias castigadas por las crisis económicas y sociales (Retis 2006). Esta coyuntura marca en España lo que en su momento se consideró la época de «los preferidos del siglo XXI»(Izquierdo, López y Martínez, 2002): los latinoamericanos irrumpieron en el contexto migratorio extracomunitario en condición preferencial tanto en las administraciones públicas como en el sector empresarial y en el clima de opinión (RETIS, 2006).

Entre finales del siglo pasado y la primera década de éste, la acrecencia de latinoamericanos se hizo una constante en las contabilidades 
anuales españolas. Bolivianos, venezolanos, paraguayos y uruguayos se sumaron a los flujos latinoamericanos precedentes y se concentraron principalmente en entornos urbanos para, posteriormente, dispersarse hacia zonas agrícolas que requerían mano de obra extranjera. Aunque la crisis económica desatada en 2008 supone un aletargamiento en los desplazamientos migratorios internacionales, las diásporas latinoamericanas que se han venido asentando en España en las décadas recientes han propiciado complejos procesos de instalación y asentamiento en las prácticas comunicativas y de consumo, jugando éstas un papel central.

El incremento de la inmigración extracomunitaria tuvo un efecto pernicioso en la opinión pública española, debido a que la prensa de referencia tendía a representarla principalmente en su condición de conflicto social, con un profundo desconocimiento de las condiciones socioeconómicas estructurales y políticas que propiciaron la llegada de trabajadores extranjeros y sus familias. En el caso latinoamericano, como hemos anotado en otros trabajos, los ecuatorianos fueron percibidos desde una mirada compasiva, situando su condición de pobres económicos y de agencia; los colombianos fueron principalmente representados desde una mirada atemorizada, muy relacionada a las imágenes de Colombia como la metáfora del horror, la delincuencia y el narcotráfico. Sólo en el caso argentino encontramos una mirada fraternal, al ser considerados como hijos y nietos de los españoles migrantes en Argentina (RETIS, 2006).

La condición de las familias transnacionales fue ignorada en el «debate social» (BAÑÓN, 2002), pues en las sociedades receptoras el discurso público tiende a representar a los migrantes esencialmente como trabajadores masculinos, temporales y desarraigados de sus lugares de origen (RETIS, 2006). Los jóvenes latinoamericanos fueron escasamente motivo de interés para la prensa española y cuando aparecieron en los titulares fue principalmente en su condición de causantes de conflicto (RETIS; GARCÍA, 2009). Y tal como ocurre en el discurso de la prensa generalista estadounidense, las mujeres latinoamericanas fueron motivo de interés de los medios españoles en mayor medida por su condición de 
víctimas o generadoras de conflicto (RETIS; GALÁN, 2010). Los efectos del discurso público dominante tuvieron eco en la opinión pública que empezó a colocar a la inmigración como uno de los principales problemas de preocupación. Sin embargo, desde las organizaciones no gubernamentales, la academia y los sectores más progresistas, se empezaron a generar sinergias para fomentar una mejor comprensión de la llegada y asentamiento de trabajadores extranjeros y sus familias (RETIS, 2006).

En otros trabajos hemos anotado cómo frente a las estrategias del discurso público dominante se generaron otras sinergias discursivas sobre la presencia de latinoamericanos en España. Por un lado, el discurso publicitario propiciado por los negocios en torno a la inmigración promovieron una percepción más positiva: los inmigrantes se convirtieron en «clientes», independientemente de su condición administrativa. Así durante los primeros años después del cambio de siglo, los anuncios publicitarios que daban la bienvenida a los nuevos usuarios de telefonía móvil y servicios bancarios convivieron con discursos discriminatorios en los medios informativos y la producción de ficción (RETIS; GALÁN, 2010). Por otro lado, las necesidades de comunicación inmediata y mediada por parte de los latinoamericanos generó nuevas formas de producción, distribución y consumo de medios. Así, junto con la formación y consolidación de asociaciones y grupos culturales inmigrantes, vieron la luz los medios diaspóricos: aquéllos que comenzaron a generar formas alternativas de autorepresentación, de distribución de información específica y espacios de promoción y publicidad (RETIS, 2008).

$\mathrm{El}$ «boom» de los medios dirigidos a inmigrantes de mediados de los dos mil, propició, entre otras cosas, que las agencias especializadas en estudios de mercado empezaran a interesarse por tener un conocimiento más específico sobre los comportamientos de consumo. A partir de entonces se generaron iniciativas por acceder a un mejor conocimiento sobre el comportamiento de los latinoamericanos en términos de consumo. En el terreno académico resulta central avanzar en dos áreas de investigación: por un lado la producción y distribución de medios en el 
contexto transnacional; por otro lado, las prácticas de consumo cultural de los latinoamericanos en el vivir transnacional (RETIS; SIERRA, 2011). El reciente incremento de latinoamericanos en ciudades con larga trayectoria en recepción de extranjeros como Londres, París, Toronto o Sydney, viene siendo apuntado por investigadores que destacan la escasez de estudios sobre estos grupos considerados como minorías dentro de las minorías, especialmente en ciudades catalogadas como hiperdiversas (GUARNIZO, 2008; BERMÚDEZ, 2008; BLOCK, 2008; PRICE; BENTON-SHORT, 2007; RETIS, 2010). Más se conoce sobre las condiciones de llegada y asentamiento en los dos principales países receptores de flujos latinoamericanos. En Estados Unidos ciertas ciudades continúan siendo los principales centros de concentración demográfica de hispanos, tal es el caso de Los Ángeles, Miami, Nueva York o Chicago. En España, la mayor parte de los latinoamericanos se concentra especialmente en Barcelona, Madrid, Murcia, Valencia y Alicante. Como consecuencia, el estudio comparado sobre producción, distribución y consumo de medios y prácticas culturales es un área fértil porque nos permite comprender el comportamiento de las diásporas latinoamericanas en contextos migratorios.

\section{El consumo cultural de los latinoamericanos en España}

Existen escasos estudios sobre consumo cultural de los inmigrantes extracomunitarios en España. En la mayor parte de las investigaciones sociológicas, los asuntos del consumo aparecen diametralmente en torno a estudios de corte etnográfico sobre las condiciones de vida de estos grupos. Estas investigaciones previas nos ayudan a esbozar facetas indicativas de las tendencias sobre prácticas culturales, consumo mediático, consumo de nuevas tecnologías y servicios afines por parte de los inmigrantes en España. ${ }^{3}$ En uno de los primeros análisis sobre la temática,

3 En total nos apoyamos en estudios cuantitativos como los datos que revela la Encuesta Nacional de Inmigrantes de 2007, con los datos básicos, que se encuentran en la web del Instituto Nacional de Estadística (http://www.ine.es) y las observaciones de expertos, tanto en el Informe elaborado para el Ministerio de Trabajo e Inmigración (VVAA, 2008), como el estudio del Colectivo Ioé y Fernández (2008), las encuestas de la Asociación para la Investigación de la Comunicación 
el Colectivo Ioé advertía las complejidades del objeto de estudio. En su propia revisión de investigaciones previas sobre el tópico, critican "la acumulación descriptiva de datos etnográficos sobre colectivos muy heterogéneos agrupados en categorías generalistas y demasiado confusas, atravesadas, en este sentido, por un marcado etnocentrismo" (IOÉ, 2001, p. 18). ${ }^{4}$ Las observaciones sobre los grupos de inmigrantes, en su criterio, tienden a yuxtaponer contenidos o rasgos de cada colectivo sin profundizar en el problema de la coherencia simbólica y material que mantienen unos con los otros. Con todo, ya a comienzos de la década, reconocen hallazgos en las pautas de comportamiento: a) la importancia del consumo televisivo dentro de los consumos culturales de las mujeres marroquíes; b) la importancia de los espacios públicos relacionales como las grandes superficies comerciales, los bares y las mezquitas, en el caso de los hombre marroquíes; c) los intercambios de productos ligados a los viajes a los países de origen, en el caso de las familias marroquíes; d) los centros de acogida y pisos compartidos como espacios relacionales de las mujeres dominicanas; e) las peluquerías (mujeres), pubs y discotecas (mixtos) y parques y otros espacios abiertos ligados al consumo y ocio, en el caso de los inmigrantes latinoamericanos.

Coincidimos con Ioé en que resulta imprescindible evitar la tentación de la descripción etnocéntrica de rasgos y prácticas para comprender y analizar principios simbólicos y materiales estructurantes de éstas. Para tal fin, afirman, es necesario propiciar tres rupturas:

1. Dejar de lado la categoría de «colectivos» según sus orígenes nacionales o regionales, para pasar a «unidades familiares» como unidades

(AIMC, varios años), los sondeos de AC Nielsen y de la Asociación para el Conocimiento de la Población Inmigrante (2005; 2004). Entre las aproximaciones cualitativas encontramos estudios sobre consumo cultural de inmigrantes latinoamericanos en España (SANTAMARINA, 2007), Madrid (CALLEJO, 2005; DIAZ NOSTY, 2007a) Cataluña (HUERTAS, 2009; HUERTAS et al, 2010; CHAVERO; GARCÍA, 2005) y Andalucía (GONZÁLEZ, 2005).

4 Tres rasgos fundamentales podríamos subrayar en relación a estos tratamientos: a) la constatación de la "diversidad" y la "diferencia" que separa los hábitos y concisiones de vida de los diferentes colectivos en función de sus lugares (países y continentes) de procedencia; b) el papel de la estructura de las "unidades familiares transnacionales" en la regulación de dichos hábitos y condiciones de vida; $y, c)$ el papel de las "redes sociales" trabadas en torno a dichas unidades en los países de acogida en relación a los mismos”. 
transnacionales, considerando su doble determinación según las relaciones de emigración y emigración.

2. Diferenciar las unidades familiares transnacionales, de carácter más inmediato, de las redes sociales migratorias en toda su amplitud.

3. Comprender las relaciones entre las redes migratorias y las estrategias identitarias que, generalmente, están marcadas de ambivalencias: “muy a menudo se clasifican las prácticas de los grupos en relación a dos polos: la separación o exterioridad, característica de los inicios de los itinerarios de acoplamiento e inserción en la sociedad de destino; la asimilación o integración, ligada a los procesos de normalización que caracterizarían los procesos de consolidación y asentamiento (...) este planteamiento supone una progresión unidireccional de los colectivos inmigrantes que se moverían siempre desde un "afuera" hacia un "adentro".

Un elemento de vital importancia en el análisis del consumo cultural es el del espacio local y sus relaciones con los medios de comunicación. En su análisis sobre consumo televisivo en el sur de Madrid, Callejo (2005) retoma la preocupación por la infravaloración del espacio. En su perspectiva, algunos aspectos de la globalización parecían indicar la evaporación del concepto espacio, pues dejaba de tener relevancia en las prácticas cotidianas. Justamente en donde se tenía tal sensación era en los análisis de consumo, pues tendían a recalcar las semejanzas en las prácticas de consumo aunque no se extendían del mismo modo en las sociedades (BAUMANN, 1999): "Es más, si había espacios prácticamente idénticos en todos los lugares del mundo, con lo que se tenía

5 Las estrategias identitarias podrían, por el contrario, contener la posibilidad para los sujetos de recuperar simbólicamente el control individual de un destino indisociablemente individual y colectivo [Oriol, 1985]. Considerar esta posibilidad supone la distinción entre "cultura" e "identidad": mientras que el primer concepto se refiere a las huellas de aprendizajes sociales inconscientes (de tal forma que puede existir una cultura aún sin consciencia identitaria); el segundo, la "identidad", se refiere a normas de pertenencia, a oposición simbólica consciente (de tal forma que la consciencia identiraria se apoyará siempre en una cultura re-construida por los sujetos, una cultura de segundo orden) [Oriol, 1985]. La reafirmación identitaria supone pues, participar en un principio colectivo consciente de organización de conductas. Se trata de una manera de situarse y no el producto cuasi-natural de una tradición preservada (IOÉ, 2001).

6 Baumann, 1999: Trabajo, consumismo y nuevos pobres. Gedisa, Barcelona. Citado por Callejo, 2005 . 
pérdida de particularidad de los propios espacios, eran los espacios de consumo (CANCLINI, 1997) dentro del proceso de racionalización de éste (RITZER, 1999; RITZER; MILES, 1998)". P Para Callejo existen dos tendencias opuestas. Del lado de la globalización tira especialmente el mercado. Del lado de la proximidad tira especialmente la sociedad. La modernidad, entiende, puede interpretarse como la configuración y articulación de tres sistemas sociales: el sistema-sociedad, el sistema-mercado y el sistema-medios de comunicación. La extensión de la modernidad por tanto, conlleva la de sus tres sistemas base. Esto supone la conquista de los tres sistemas del propio mundo de vida. Pero además, la mundialización de los tres sistemas, que a su vez se articulan en un sistema social-mundo. En este proceso, la relación entre lo local y los medios de comunicación suele ser única. Callejo propone entender los medios en relación a tres funciones con respecto a los espacios locales o de proximidad:

1. Función dominante, como generadores de un mercado mayor, a escala planetaria. Y en este terreno, la ciudadanía deriva del consumo.

2. Función reguladora de mercados locales relativamente autónomos.

Deriva de la existencia de un mercado local, con oferta y demandas locales, a los que sirve el medio.

3. Función de productores de ciudadanos, preocupados por las formas de integración de la localidad en el sistema-mundo

En su estudio sobre los municipios madrileños, Callejo apunta la incorporación de los inmigrantes extranjeros a poblaciones integradas por inmigrantes nacionales de los años setenta. Esto hace que Madrid Sur sea un experimento social donde pueden observarse incipientemente algunas características de las sociedades del futuro, como el encuentro entre varias culturas. En su estudio, identifica en los inmigrantes extranjeros una concepción menos restrictiva y más integradora que los grupos nacionales, abriendo el concepto de cultura a lo universal. En el análisis del trabajo de campo, que combinó encuestas telefónicas con grupos de discusión y entrevistas en profundidad, encontró que en los grupos con

7 Citados por Callejo, 2005 
una concepción más restrictiva de la cultura (como el personal profesional, por ejemplo), la televisión es atacada como un enemigo de ésta. En los grupos con una concepción menos restrictiva de la cultura (como trabajadores, inmigrantes y jóvenes no universitarios), la televisión no aparece como un elemento excluido en el discurso sobre la cultura. ${ }^{8}$

Más recientemente, Santamarina (2007) realizó un estudio cualitativo sobre el consumo y el ocio de los inmigrantes latinoamericanos en España. El trabajo de campo se centró en la realización de grupos de discusión de jóvenes y mujeres latinoamericanas residentes en Madrid y Murcia. Para esta investigadora, la importancia del consumo reside en su carácter institucional, que alcanza un lugar hegemónico cuando se trata de sociedades pertenecientes a economías abiertas a la lógica del mercado. Por su parte, los trabajos sobre consumo cultural y consumo mediático de los inmigrantes latinoamericanos en Cataluña nos ofrecen, también, apuntes sobre las tendencias en el comportamiento de estos grupos en otras áreas geográficas. Huertas (2009) utilizó el aporte estadístico del Barómetro de la Comunicación y la Cultura que trabajó con una muestra de españoles y extranjeros complementando los datos cuantitativos con 20 entrevistas en profundidad. El estudio apunta que la mayoría de los latinoamericanos vive en hogares formados por parejas con hijos (51\%), aunque es significativo el número de núcleos familiares sin descendencia $(22,4 \%)$. La mayoría vive en régimen de alquiler $(61,9 \%)$, aunque con un notable porcentaje de propietarios (34,3\%). Los datos, referentes al 2006, muestran que la mitad de los latinoamericanos cobraba menos de 900 euros mensuales. Huertas retoma la transición que hace unos años propició empezar a trabajar con el concepto de "migración transnacional", que supuso un paso respecto a la idea de

8 Entre algunos de estos grupos -sobre todo, entre los entrevistados- hay que señalar que la posición contra la inclusión de la televisión en la cultura se vincula con lo comercial. La televisión sería el principal productor de mercancía cultural industrial, lo que prácticamente no deja espacio para la producción y gestión artesanal de la cultura, que es la posición material ideológica en la que preferentemente están los que la reivindican. Así nos encontramos con la aparente paradoja de que la televisión queda excluida de su concepción de la cultura y, sin embargo, se la tiene como la principal fuente de productos que podrían denominarse culturales (cantantes, artistas, actores, películas, etc.), por lo tanto, la principal productora de demanda cultural. (ibid: 118). 
"sociedad posnacional", y que nos permite mantener la idea de trabajar con la perspectiva de migrantes internacionales desplazados desde sus lugares de origen, pero sin romper los lazos y las comunicaciones transfronterizas. En este sentido, el rol central de los medios de información y comunicación permite recomponer las relaciones cotidianas en lazos transnacionales, tanto con los afectos y relaciones familiares como con las relaciones grupales, barriales y hasta nacionales. Huertas propone tres posicionamientos respecto a los tipos de actividad cultural: a) la posición segregacionista, desde la que el inmigrante asume el consumo de productos ofrecidos de manera sesgada para su colectivo; b) la posición integradora, que permitiría identificar aquel inmigrantes que no evalúa preconcepciones sobre el origen geográfico de los contenidos a la hora de realizar su consumo; c) la posición asimilacionista, que la ubica en los casos en los que el inmigrante intenta responder al arquetipo de la población autóctona que lo llevaría al extremo de despreciar sus raíces culturales.

El riesgo de establecer categorías de clasificación de las prácticas culturales reside en presuponer que las actitudes individuales y colectivas son inamovibles y certeras. Proponemos, más bien, repensar las prácticas en su carácter dinámico y muchas veces contradictorio. Las aproximaciones cualitativas en el tiempo nos pueden brindar pistas de reacomodos, de sinergias y de incongruencias en los comportamientos. La naturaleza dinámica de las migraciones es tal que los hallazgos encontrados en un estudio puntual resulten obsoletos en un lapso de dos o tres años. La coyuntura de la crisis, por ejemplo, viene propiciando nuevos desplazamientos de trabajadores migrantes. La movilidad interna e internacional escapa de las previsiones estadísticas y, por ahora, sólo es perceptible en el terreno del trabajo de campo.

En otra investigación que venimos realizando sobre medios étnicos en «ciudades globales», ${ }^{9}$ nos encontramos en la inauguración de la Casa Ecuador en Londres. En el evento la Secretaría Ecuatoriana

9 Un trabajo que venimos realizando desde la Universidad Estatal de California Northdrige titulado "Medios étincos en «ciudades globales»: Los Angeles, Madrid, Londres". 
del Inmigrante (SEMI) hacía evidente el reconocimiento de un nuevo flujo de migrantes ecuatorianos hacia la capital inglesa, algunos de ellos provenientes de España. Ese mismo fin de semana entrevistamos a un adulto joven de Pereira, residente en España, pero que acaba de abrir en Londres un restaurante de comida colombiana con su madre, residente en el Reino Unido. En una zona de la periferia inmediata al centro del Londres, donde se reúnen las actividades de comercio, ocio y cultura de los inmigrantes extracomunitarios, el muchacho nos comentaba su intensión de iniciar un segundo proceso migratorio desde el Levante español, donde siguen residiendo su mujer y sus dos hijos pequeños, hacia la capital británica. El paro sostenido ha incentivado a este joven a rediseñar un nuevo proyecto de vida, situación que se replica con una mujer boliviana que vende pan con queso al otro extremo de la ciudad, en otro polo de concentración de migración extracomunitaria en Londres. Mientras metía sus masas de pan, esta mujer de mediana edad, nos explicaba su proyecto de retorno y cómo cada vez ve menos paisanos en el metro de la ciudad; en su percepción: una muestra de los procesos de retorno. En Nueva York, un taxista ecuatoriano nos comenta que sus familiares y amigos le han pedido ayuda para incorporarse al mercado laboral de la ciudad y que, probablemente, estén dejando los crecientes desplazamientos de portorriqueños hacia otras áreas como Boston y Orlando. Estas experiencias individuales, muestran tendencias sobre nuevos procesos migratorios transfronterizos. Los proyectos, por tanto, no resultan inamovibles, sino que se transforman como consecuencia de las condiciones coyunturales. Este es un elemento que tenemos que tomar en cuenta en nuestras interpretaciones sobre los procesos diaspóricos.

\section{La centralidad de los medios en el contexto migratorio}

Los trabajos de Huertas y otros (2009, 2010), así como el de Chavero y García-Muñoz (2005) son pioneras aproximaciones cualitativas al conocimiento del consumo mediático por parte de los inmigrantes latinoamericanos en Cataluña. Así apuntan a la televisión como el 
medio hegemónico en la dieta de los latinoamericanos, con una alta penetración de las cadenas estatales y con el porcentaje de penetración más bajo de la televisiones autonómicas en el grueso de los inmigrantes extracomunitarios. Y anotan también el moderado incremento de las nuevas tecnologías en los hogares de latinoamericanos en Cataluña. Estas investigaciones apuntan la elevada actividad cultural tanto de los medios de comunicación como en los relacionados con bienes y servicios culturales disponibles. Sería la tipología del consumo integrador la que prevalece y remarcan el uso de los medios para aprender el catalán (HUERTAS, 2009), así como para conocer mejor a la comunidad en la que se reside (CHÁVERO; GARCÍA-MUÑOZ, 2005).

En los años recientes se han realizado algunos estudios cuantitativos de audiencias inmigrantes, tanto a nivel de Madrid como en el territorio nacional. En una reciente investigación dábamos cuenta de los primeros sondeos públicos en este aspecto (RETIS, 2006). En su boletín informativo de octubre de 2004, la Asociación para la Investigación de Medios de Comunicación (AIMC, 2004) presentó un primer sondeo sobre el comportamiento de los inmigrantes en el consumo de medios de comunicación. Con las advertencias sobre ciertos sesgos que condicionarían la infraestimación del grupo analizado, se desveló la comparativa respecto a las audiencias españolas: menor consumo de periódicos, similar uso de revistas y un mayor consumo de Internet. En esos años, la encuesta encontró que los inmigrantes escuchaban menos radio en su conjunto, pero la temática en contenidos musicales conseguía una mayor penetración. Se anotó también un menor número de horas de televisión al día. Tres años más tarde se hicieron públicos los estudios de la agencia de investigación de mercados AC Nielsen y el Estudio de Medios Inmigrantes, de la Asociación para el conocimiento de la población inmigrante (ACPI). Este estudio identificó cinco tendencias: a) que los inmigrantes consumen menos horas de televisión que los españoles, y que tienen un creciente consumo de canales internacionales; b) que los inmigrantes tienen un mayor consumo de radio, con una notable preferencia por las estaciones musicales; c) que los inmigrantes tienden 
a consumir más medios gratuitos que de pago; d) su consumo de medios dirigidos a inmigrantes es mayor que la prensa generalista; e) un destacado uso de nuevas tecnologías. En octubre del 2005, AIMC publicó estimaciones sobre el comportamiento de las audiencias inmigradas en España. En este documento advierte de la problemática para que estos grupos sean representados en el Estudio General de Medios (EGM). En su estudio se arrojaron nuevos datos que nos da pistas para entender las tendencias comparativas entre los latinoamericanos y los españoles: a) aquellos leen menos diarios pero más revistas que éstos, b) su consumo de Internet es semejante, c) los latinoamericanos escuchan más radio temática y menos generalista.

Entre mayo y junio EMI de 2008 encuestó a 3,215 residentes en la Comunidad de Madrid, la provincia de Barcelona y el Gran Levante (provincias de Castellón, Valencia, Alicante, Murcia y Almería). Sus resultados confirmaron una penetración moderada de los semanales para inmigrantes de carácter gratuito (27\%), seguido de los gratuitos generalistas $(24,3 \%)$, los mensuales dirigidos a inmigrantes $(24,3 \%)$ y los diarios generalistas y deportivos (14,9\%). Entre los periódicos generalistas que más lee la población inmigrante en el 2008, se encuentra el diario El País (98,8\%), el Marca (72,5\%) y El Mundo (52\%). ${ }^{10}$ Más de la mitad de los inmigrantes encuestados afirmaron que no van nunca al cine (57,6\%), mientras que el 42,4\% reconoció que asiste alguna vez. De estos, la mayoría comenta que va una vez al mes en promedio, o que en un año puede verse entre 5 y 6 películas. Respecto al consumo de radio, la encuesta reveló que tres cuartas partes se considera un radioescucha habitual $(71 \%)$, mientras que un $28,9 \%$ afirma que no la escucha nunca o casi nunca. De quienes siguen la programación radiofónica, la mayoría lo hace diariamente o entre 3 y 4 días a la semana. Casi la totalidad de los encuestados reconoció ver la televisión (97\%) y que lo hace todos los días.

10 Le siguen, en orden decreciente: La Vanguardia (41,7\%), As (40,7\%), El Periódico de Cataluña (31,9\%), ABC (25,5\%), El Mundo Deportivo (23,2), El Levante (21,8\%), Sport (21,4\%), La Razón (19,1\%), La Verdad de Murcia (16,8\%), Información de Alicante (11,7\%), Las Provincias (7,3\%), Público (4,0\%), La Voz de Almería (3,3\%). 
La penetración del teléfono móvil aparece en este estudio con un fuerte peso específico (94.9\%), un porcentaje mucho más alto que el teléfono fijo $(72,3 \%)$. Sin embargo, los encuestados reconocieron que en los hogares no resulta habitual tener conexión a Internet. Sólo el $27,8 \%$ de los encuestados confirma tener este servicio en sus casas. Un dato indicativo es que a pesar de no contar con conexión en casa, la mitad de los entrevistados reconoció haberse conectado el día anterior a la fecha de la entrevista $(52,5 \%)$ o haberlo hecho en algún momento de la semana reciente $(33,7 \%)$, por lo que se deduce que continúan utilizando los servicios de Internet ofrecidos en locutorios, cibercafés, bibliotecas, etc. Y cuando acceden a la red, lo hacen mayoritariamente para utilizar el correo electrónico, ver páginas web o chatear. También reconocen leer noticias sobre el país de origen o noticias en general. Muy por debajo en la comparativa aparecen los usos de descargas de archivos, videoconferencias telefonía IP, escuchar radio, realizar operaciones bancarias, comprar, Messenger, estudiar, ver televisión, escuchar música o jugar. ${ }^{11}$

Los datos del Estudio General de Medios publicados en 2008, nos dan una primera aproximación al comportamiento de los usuarios y las audiencias por colectivos nacionales. La tabla 1 nos permite esbozar una aproximación más detallada sobre las prácticas y, en concreto, nos ayuda a acercarnos a los grupos de ecuatorianos y colombianos. Según se deduce de este sondeo, el 34\% de los ecuatorianos lee diarios, mayormente por su información general y en menor medida por la información deportiva. Casi la mitad reconoce leer revistas, especialmente las mensuales. La penetración de los diarios en los colombianos es ligeramente superior (38\%) y reflejan proporcionalmente semejantes intereses por tópicos. Es decir, que se compra la prensa para informarse

11 Respecto a otros productos y servicios disponibles, más de la mitad de los entrevistados afirma disponer de vehículo propio (62,5\%); sin embargo, sólo el 29,2\% respondieron tener carnet de conducir. El 21,2\% tiene video consola. Respecto a la vivienda, el 64,8\% alquila su vivienda, el 11,1\% alquila una habitación, el 0,9\% trabaja como interna. El 21,9\% posee vivienda propia. El 62,5\% envía remesas a su país de origen regularmente. 
de las noticias en general y para revisar los resultados de los últimos partidos o campeonatos.

Tabla 1. Inmigrantes latinoamericanos en España: Consumo de publicaciones

\begin{tabular}{llllllllll}
$\begin{array}{l}\text { Penetra- } \\
\text { ción } \%\end{array}$ & $\begin{array}{l}\text { Total } \\
\text { Diarios }\end{array}$ & $\begin{array}{l}\text { Info } \\
\text { General }\end{array}$ & $\begin{array}{l}\text { Info } \\
\text { Depor. }\end{array}$ & $\begin{array}{l}\text { Info } \\
\text { Econ. }\end{array}$ & Suplem & $\begin{array}{l}\text { Total } \\
\text { Revistas }\end{array}$ & Sem & Quin & Mens \\
\hline Españoles & 40,7 & 37,1 & 10,0 & 0,6 & 26,4 & 49,6 & 23,1 & 3,1 & 38,4 \\
Extranjeros & 31,2 & 28,6 & 7,2 & 0,3 & 13,0 & 47,4 & 18,0 & 4,1 & 39,7 \\
Ecuador & 34,1 & 31,4 & 8,0 & 0,5 & 12,0 & 51,3 & 23,9 & 6,0 & 42,3 \\
Colombia & 34,8 & 32,9 & 6,3 & 0,3 & 13,0 & 59,5 & 21,2 & 4,5 & 48,7 \\
Bolivia & 34,4 & 32,9 & 6,7 & 0,6 & 9,4 & 42,4 & 16,1 & 2,7 & 34,2 \\
Argentina & 34,7 & 32,3 & 7,4 & 0,0 & 21,1 & 61,4 & 18,6 & 1,0 & 54,4 \\
Perú & 50,8 & 46,0 & 16,2 & 0,0 & 14,5 & 56,0 & 22,8 & 6,6 & 43,7 \\
Brasil & 33,9 & 30,7 & 8,6 & 0,0 & 14,0 & 49,2 & 15,9 & 3,9 & 44,1 \\
Rep. Dom. & 30,0 & 27,1 & 4,6 & 0,0 & 21,3 & 52,5 & 25,9 & 5,8 & 43,0 \\
\hline
\end{tabular}

Fuente: Estudio General de Medios. Datos citados en: Gabardo y Santiago, 2008.

En términos de medios masivos, como muestra la tabla 2, la penetración de la televisión es superior en los ecuatorianos que en los colombianos (56,5\% respecto al 51,6\%), ligeramente por debajo de la media española. En la comparativa de las escuchas radiofónicas las proporciones se muestran semejantes: son más ecuatorianos que colombianos los que escuchan radio (56,5\% frente a 51,6\%) y también gustan más de radio temática (41,5\% frente a 39,5\%). Sin embargo, las proporciones se invierten cuando hablamos de radios generalistas. Son más colombianos los que sintonizan cadenas de contenido variado $(10,5 \%$ ante $6,3 \%)$.

La Encuesta de 2007 nos ofrece datos valiosos sobre comportamientos sociales. A partir de las interpretaciones de los expertos y corroborando las cifras del informe estadístico podemos conocer por ejemplo el estado civil de los adultos provenientes de Latinoamérica en España: el $45 \%$ está soltero y el $8 \%$ ha enviudado. En las respuestas de los entrevistados 
se identificó que la mayoría de los hombres ecuatorianos o bolivianos tiende a tener parejas provenientes de sus países de origen (90\% de los casados), así como las mujeres bolivianas (más del 85\%). Un tercio o más de las mujeres colombianas, argentinas o peruanas ha establecido relaciones con algún español. Más de la cuarta parte de los hombres argentinos y peruanos tiene pareja española. Los datos de la encuesta ayudan a identificar a quienes aún viven separados de sus cónyuges, es decir, manteniendo la estructura de familia trasnacional. En este sentido destacan los provenientes de Bolivia (34\% de hombres y $21 \%$ de mujeres), Perú (26\% y 24\%), Ecuador y Colombia (más del 20\% de los hombres). De las 240.000 parejas transnacionales, 84 mil proceden de América Latina: 20.000 de Ecuador, y más de 10.000 en el caso de los colombianos, peruanos y bolivianos (ENI, 2007).

Tabla 2. Inmigrantes latinoamericanos España: Consumo de Medios

\begin{tabular}{llllllll}
\hline Penetración \% & $\begin{array}{l}\text { Total } \\
\text { Radio }\end{array}$ & $\begin{array}{l}\text { Radio } \\
\text { Gen. }\end{array}$ & $\begin{array}{l}\text { Radio } \\
\text { Temática }\end{array}$ & Total TV & Cine & $\begin{array}{l}\text { Internet } \\
\text { Ayer }\end{array}$ & $\begin{array}{l}\text { Exterior } \\
\text { Ayer }\end{array}$ \\
\hline Españoles & 56,8 & 30,8 & 29,6 & 89,3 & 5,3 & 26,2 & 50,9 \\
Extranjeros & 47,1 & 8,8 & 37,1 & 83,7 & 5,3 & 26,6 & 60,8 \\
Ecuador & 56,5 & 6,3 & 47,5 & 88,3 & 6,8 & 19,1 & 65,8 \\
Colombia & 51,6 & 10,5 & 39,5 & 85,8 & 5,0 & 32,9 & 67,6 \\
Bolivia & 50,5 & 7,3 & 41,5 & 87,4 & 4,4 & 16,8 & 64,2 \\
Argentina & 52,0 & 11,7 & 42,0 & 83,6 & 7,4 & 45,3 & 61,3 \\
Perú & 55,1 & 7,9 & 50,5 & 86,2 & 7,9 & 41,4 & 73,8 \\
Brasil & 42,6 & 4,2 & 39,5 & 78,3 & 11,3 & 44,8 & 61,7 \\
Rep. Dom. & 46,4 & 8,7 & 37,6 & 84,2 & 5,4 & 14,1 & 53,3 \\
\hline
\end{tabular}

Fuente: Estudio General de Medios. Datos citados en: Gabardo y Santiago, 2008.

Entender las complejidades de los hogares de los latinoamericanos en España nos permite también comprender las diversas variables que pueden influir en las prácticas de consumo cultural, especialmente en lo referente a los medios de comunicación. Según los datos de la encuesta, nos encontramos ante un grupo indicativo de hogares multinacionales. Este dato nos da pistas sobre formas de negociación de los consumos 
colectivos y las prácticas culturales directas y mediadas. La encuesta indica que en la mitad de los hogares de los latinoamericanos (53\%) todos los miembros nacieron fuera de España: $60 \%$ en los hogares bolivianos y peruanos, $58 \%$ de los hogares ecuatorianos, $55 \%$ de los argentinos. Los latinoamericanos presentan menos hogares unipersonales que la media general de los inmigrantes en España. En el caso de los bolivianos, por ejemplo, es casi inexistente. En menos de la mitad de los hogares latinoamericanos viven exclusivamente familiares directos (48\%): sólo en el 19\% de los hogares bolivianos, seguidos de colombianos, peruanos y ecuatorianos; siendo casi inexistentes en los argentinos. Estos hogares multinacionales nos permiten inferir procesos de convivencia en la que también se producen prácticas trasnacionales (ENI, 2007). La población que más habitualmente forma hogares donde conviven varias nacionalidades son los provenientes de Ecuador (13\% de los hogares), especialmente con otros latinoamericanos, particularmente de Bolivia, pero también de Colombia y Perú. Un caso significativo es el de los hogares colombianos (9\%), que conviven principalmente con personas de Bolivia y Ecuador. El 8\% de los hogares argentinos convive con peruanos y bolivianos; mientras que el 7\% de los hogares bolivianos convive con argentinos y peruanos (ENI, 2007).

\section{Las familias transnacionales latinoamericanas}

De los 425.000 padres y madres menores de 45 años que tienen a sus hijos en el país de origen, la mayoría procede de América Latina (245.000). ${ }^{12}$ Por colectivos nacionales los más notables son los padres nacidos en Ecuador (73.000), seguidos de Bolivia (50.000), Colombia (42.000) y Perú (18.000). Si se concentra la atención en los padres y madres menores de 45 años, se advierte que el 30\% de los latinoamericanos tienen a sus hijos en sus países de origen: $54 \%$ de los bolivianos, $32 \%$ de peruanos y ecuatorianos, 30\% de colombianos y $7 \%$ de argentinos. Entre esta población de hijos separados de los padres existen potenciales flujos de

12 De las personas de 16 y más años con hijos destacan los ecuatorianos (72\%), seguidos por colombianos y bolivianos (68\%) (ibid). 
nueva inmigración (ibid; 57-58). Una gran mayoría de los extranjeros residentes en España tiene al menos uno de sus progenitores vivos: el 77\% de los inmigrantes latinoamericanos cuenta con sus padres. Del total de los inmigrantes, algo más de la mitad (48\% de los padres y $43 \%$ de las madres) está instalado en España, mientras que la otra mitad viven en los países de origen (48\% de los padres y 54\% de las madres). Esto nos permite comprobar la existencia de los lazos familiares establecidos en espacios transnacionales transfronterizos (ibid: 60).

Aunque los proyectos migratorios pueden estar variando en estos momentos debido a la coyuntura económica y social, la encuesta de 2007 nos permite esbozar una fotografía más o menos fiel respecto a los planes de los extranjeros residiendo en España para los próximos cinco años. Así sabemos que el $81 \%$ de los adultos tiene decidido permanecer en este país, mientras que el $8 \%$ reconoció que podría marcharse $(7 \%$ a su país, $1 \%$ a otro distinto). Un $11 \%$ de los entrevistados afirmó no tener una decisión clara al respecto. Entre las personas más dispuestas a marcharse se encuentran las que al llegar a España tenían entre 20 y 34 años, las que llegaron a partir del 2002 y las que tienen entre 20 y 24 años. En otras palabras, las personas más jóvenes y las que llevan menos tiempo de residencia en España. También es más notorio en las personas con estudios superiores (9\%) y las mujeres (8\%). Respecto a los colectivos nacionales, es más evidente el deseo de volver en el caso de los bolivianos (24\%) y ecuatorianos (15\%), mientras que el $84 \%$ de los colombianos y los argentinos manifiesta una preferencia por permanecer viviendo en España. La cuarta parte del total de los entrevistados manifestó su deseo de traer a algún familiar. ${ }^{13}$

13 Entre los latinoamericanos el 78\% de los bolivianos no ha regresado nunca a su país de nacimiento, hecho que ocurre entre el $40 \%$ de los ecuatorianos, peruanos y argentinos, y el $38 \%$ de los colombianos. El $80 \%$ de los que afirmaron haber viajado lo hicieron para visitar a familiares y amigos, el $63 \%$ lo hizo para disfrutar de sus vacaciones, el 7\%, para obtener la documentación migratoria y el $5 \%$ para resolver algún asunto económico. De entre los que invierten más días en la estancia destacan los bolivianos ( 52 días) y los ecuatorianos (más de 45 días). 


\section{Prácticas transnacionales: envíos de remesas y comunicación}

Más del $60 \%$ de los ecuatorianos, colombianos y bolivianos, y casi la mitad de los peruanos, envían mensualmente dinero a sus países. La suma promedio anual de los envíos del 2006, refleja que los hombres colombianos y peruanos enviaron más de 2.500 euros; mientras que las mujeres ecuatorianas, colombianas, bolivianas y peruanas enviaron más de 2000 euros. Los envíos son realizados especialmente a los padres (62\%, especialmente ecuatorianos). Una cuarta parte envía el dinero a sus hijos (especialmente bolivianos y peruanos). El 23\% dirige las remesas a un hermano o hermana (particularmente colombianos). La mitad de los envíos se realizan por agencia especializada (52\%), el 28\% utiliza transferencias bancarias y el $14 \%$ realiza giros postales. Un $6 \%$ aprovecha el viaje de algún conocido para el encargo. Más del 55\% de los bolivianos y los colombianos utiliza el locutorio o la agencia de envíos para realizar sus remesas, más del 35\% de los peruanos y los argentinos prefieren la transferencia bancaria. El 15\% de los colombianos y el 26\% de los argentinos utiliza el giro postal.

El 90\% de los inmigrantes encuestados mantiene contacto con el país de origen. En el caso de los latinoamericanos esta cifra sube a 95\%, especialmente en los procedentes de Ecuador, Colombia, Bolivia y Perú. Ligeramente más bajo se encuentra Argentina, con un 93\%. El medio más utilizado es el teléfono (97\%). El 66\% llama por lo menos una vez por semana (especialmente los colombianos y bolivianos), el $30 \%$ lo hace quincenal o semanalmente. El segundo lugar en el método de comunicación lo ocupan los servicios de Internet. Un 37\% de los inmigrados utiliza sus correos electrónicos o el chat. De éstos, el $76 \%$ lo hace semanalmente (especialmente argentinos) y el $21 \%$ quincenal o mensualmente (particularmente ecuatorianos y bolivianos), el 3\% sólo lo utiliza de manera esporádica. La comunicación por Internet es mayor en las personas menores de 20 años o, de entre 60 y 64 años con estudios superiores. El teléfono es usado con mayor frecuencia por inmigrantes 
72 ¿CONSUMIDORES O CIUDADANOS?

recientes que llegaron con 30 o más años cumplidos y tienen estudios primarios.

Tabla 3. Participación de inmigrantes latinoamericanos en organizaciones

\begin{tabular}{|c|c|c|c|c|c|c|c|}
\hline & & $\begin{array}{l}\text { Países } \\
\text { americanos } \\
\text { sin EEUU } \\
\text { CANADA }\end{array}$ & Ecuador & Colombia & Bolivia & Argentina & $\begin{array}{l}\text { Resto de } \\
\text { países } \\
\text { americanos } \\
\text { sin EEUU } \\
\text { CANADA }\end{array}$ \\
\hline Pregunta & Total & 1787691 & 371743 & 299479 & 157732 & 231630 & 727107 \\
\hline \multirow{3}{*}{$\begin{array}{l}\text { Organiza- } \\
\text { ciones de } \\
\text { ayuda al } \\
\text { inmigrante }\end{array}$} & sí & 43248 & 5221 & 9073 & 6259 & 3508 & 19188 \\
\hline & no & 1724982 & 362477 & 288328 & 150279 & 224736 & 699163 \\
\hline & $\mathrm{n} / \mathrm{c}$ & 19461 & 4045 & 2079 & 1193 & 3386 & 8757 \\
\hline \multirow{3}{*}{$\begin{array}{l}\text { Asociaciones } \\
\text { y clubes } \\
\text { deportivos }\end{array}$} & si & 41089 & 10810 & 2552 & 10164 & 2768 & 14796 \\
\hline & no & 1727141 & 356888 & 294848 & 146374 & 225476 & 703555 \\
\hline & $\mathrm{n} / \mathrm{c}$ & 19461 & 4045 & 2079 & 1193 & 3386 & 8757 \\
\hline \multirow{3}{*}{$\begin{array}{l}\text { Grupos } \\
\text { educativos y } \\
\text { culturales }\end{array}$} & si & 25880 & 3332 & 2475 & 4329 & 4513 & 11231 \\
\hline & no & 1742351 & 364365 & 294925 & 152210 & 223730 & 707120 \\
\hline & $\mathrm{n} / \mathrm{c}$ & 19461 & 4045 & 2079 & 1193 & 3386 & 8757 \\
\hline \multirow{3}{*}{$\begin{array}{l}\text { Entidades } \\
\text { y grupos } \\
\text { religiosos }\end{array}$} & si & 26301 & 3797 & 888 & 7849 & 1890 & 11876 \\
\hline & no & 1741930 & 363900 & 296512 & 148690 & 226353 & 706474 \\
\hline & $\mathrm{n} / \mathrm{c}$ & 19461 & 4045 & 2079 & 1193 & 3386 & 8757 \\
\hline \multirow{5}{*}{$\begin{array}{l}\text { Otros grupos } \\
\text { de carácter } \\
\text { social }\end{array}$} & si & 30081 & 3345 & 2530 & 6632 & 3557 & 14016 \\
\hline & no & 1738150 & 364353 & 294870 & 149907 & 224687 & 704334 \\
\hline & $\mathrm{n} / \mathrm{c}$ & 19461 & 4045 & 2079 & 1193 & 3386 & 8757 \\
\hline & Total & 1768231 & 367698 & 297400 & 156539 & 228244 & 718351 \\
\hline & $\begin{array}{l}\text { Total } \\
\mathrm{n} / \mathrm{c}\end{array}$ & 19461 & 4045 & 2079 & 1193 & 3386 & 8757 \\
\hline
\end{tabular}

Fuente: Encuesta Nacional de Inmigrantes 2007

\section{Participación en actividades asociativas en España}

Los índices de asociacionismo entre los inmigrantes son más bien bajos. Las respuestas resumidas en la tabla 3 demuestran que cuando los inmigrantes se acercan a las asociaciones lo hacen en mayor proporción a 
las entidades destinadas a toda la población, más que a las que orientan sus servicios a la población de origen extranjero. De todas las existentes, son las de carácter deportivo las que más participación consiguen (el 7\% del total de los inmigrantes, $5 \%$ en genéricas y $2 \%$ en específicas para extranjeros. El $6 \%$ se inscribe en las de origen educativo o cultural (4\% en las generales y $2 \%$ en las de extranjeros). El $5 \%$ participa de las de índole social (3\% generales y $2 \%$ para extranjeros), mientras que el $2 \%$ reconoce participar de asociaciones de carácter religioso (2\% generales y $2 \%$ para extranjeros). En el disgregado por nacionalidades observamos cómo en el terreno de las organizaciones inmigrantes se aprecia una concentración mayor de colombianos y bolivianos, mientras que en asociaciones y clubes deportivos, son los ecuatorianos los más participan. Los grupos educativos y culturales son más asiduos en los argentinos y bolivianos. En cuanto a las actividades relacionadas con entidades y grupos religiosos fueron bolivianos y ecuatorianos los que en mayor proporción aseguraron participar de alguna.

\section{Una aproximación empírica desde los discursos}

La perspectiva transnacional nos permite entender que los migrantes no rompen con los lazos personales, familiares, sociales e institucionales, ni con sus formas de pertenencia, sus emociones y sus sensaciones. En realidad, todos estos procesos se transforman, se enriquecen y se complejizan en el vivir transnacional. Los consumos culturales, por tanto, reflejan también procesos de transición entre herencias, arraigos personales y colectivos, y mutaciones hacia conformaciones nuevas que reelaboran hibridaciones culturales (CANCLINI, 1989, 2002); resulta imprescindible deconstruir las prácticas de las mediaciones en la recepción de los medios y el consumo cultural (MARTÍN BARBERO, 2006). En 2011 realizamos una investigación de carácter cualitativo que buscaba poner en consonancia las tendencias generales planteadas en sondeos y encuestas, con los discursos recogidos en entrevistas en profundidad y grupos de discusión. Se buscó también contraponer la coyuntura actual con la evidencia de las transformaciones en los procesos de producción 
y circulación de bienes culturales y comunicativos ofrecidos y consumidos preferentemente por inmigrantes latinoamericanos en España. Se trataba de analizar y comprender cómo verbalizan y/o representan discursivamente diversos aspectos de sus prácticas cotidianas individuales y colectivas.

Una de las primeras constataciones de las entrevistas es la evidencia de un proceso de evolución en la concepción del inmigrante como target de la publicidad comercial. En los años previos a la explosión de la crisis, a los estereotipos del «inmigrante extracomunitario» en el discurso de la exclusión en la producción mediática informativa y de ficción, se contraponía la irrupción de la figura del «cliente potencial» por parte del discurso publicitario (RETIS; GALÁN, 2010). Las campañas de bancos, remesadoras y telefonía representaban al inmigrante como un target de audiencia apetecible y en crecimiento. En este periodo es cuando surgen las agencias de medios de inmigrantes. Con la fundación de Minority, Mundo Etnia, Ethnical Consultants y Grupo Eñe, se consolidaba esta etapa en el plano comercial. Estas agencias se sumaron a las previsiones sobre el mercado inmigrante que ya habían lanzado en su momento las agencias como el AC Nielsen, TNS, o People Matters que incorporaron el sector inmigrante en sus estudios generales de mercado. En la primera Feria de productos y servicios para inmigrantes organizada en Madrid en 2007 acudieron 180 empresas involucradas en el sector y asiduos anunciantes en los medios étnicos. ${ }^{14}$

Por entonces, a finales del 2007, revisábamos la historia reciente de producción de medios para inmigrantes y proponíamos cuatro etapas

14 El sector financiero, que crearon firmas especializadas para captar el negocio de las remesas, un servicio en el que los canales oficiales movieron 6.250 millones de euros en 2006. Aquí participaron: Banco Popular, el Banco Santander, Banesto, Caja Madrid, Caja Navarra, el Deutsche Bank Credit, La Caixa, Credi Agil Dinero Express, Grupo Bem, Moneygram, RD Money Transfer, Safe Money Transfers, y Western Union. En el sector de la telefonía, la participación estuvo representada por: Telefónica, Orange, Vodafone, C3-Calling Card Company Spain, Digital Bells, Happy Móvil, Lebara Mobile, Lleida.net, Orbitel y Tellink Sistemas. El sector inmobiliario: como Look \& Find, Veigas Inmobiliaria, Union Andina, Grupo FDP-Obra Nueva, Grupo Inmobiliario Geconsa, Rivera Vergara, Casa Sueño, Concrisol, Marina Dor Ciudad de Vacaciones y Portal Inmobiliario De Ecuador. En el sector de la alimentación, la representacion de las empresas fue variada: Carrefour, Campofrío, Coca Cola, Gourmet Latino, Naturandina-America Import, Induveca, Opencor, Superandes, y Nativo-Goya. En el sector empleo figuraron ADECO y Opencor. 
del desarrollo: 1) el surgimiento de las iniciativas de la producción mediática a comienzos de los noventa; 2) la primera oleada de incremento de medios (2002-2003); 3) una segunda oleada de acrecencia de medios (2003-2006); y 4) la consolidación de las sinergias asociativas y de competencia directa. En esa investigación apuntábamos que, en nuestra perspectiva, el futuro inmediato de los medios étnicos en Madrid dependerían de las coyunturas económicas. Pues bien, podemos ahora hablar de una quinta etapa de recesión -que no de extinción- iniciada en el 2009 y en proceso de consolidación el día de hoy. Los medios dirigidos a inmigrantes que tuvieron un boom de crecimiento en la cima de la época de bonanza de la economía española, vienen resintiendo la drástica reducción de las inversiones publicitarias. Como consecuencia, la prensa gratuita inmigrante se ha contraído tanto en número de páginas como en monto de tiraje y canales de distribución. Estos procesos no resultan sorprendentes ni aislados. En otros países como Estados Unidos, por ejemplo, comprobamos una seria reestructuración orgánica de la producción de medios dirigidos a minorías étnicas o migrantes. Lo que sí resulta sugerente en la constatación de que, a pesar de la confluencia de la crisis económica y la reconversión tecnológica, estos medios, considerados como minoritarios, han resistido en algunos casos en mejores condiciones que los medios de referencia o mainstream. El análisis comparado de la producción de medios étnicos en ciudades como Madrid, Londres y Los Ángeles nos permite esbozar algunas pistas sobre la consolidación y acrecencia moderada de los "medios latinos" (RETIS, 2010).

En España, la incidencia de los reajustes económicos, tecnológicos y publicitarios en el terreno de los medios dirigidos a inmigrantes ha propiciado una serie de reacomodos. De las entrevistas se deduce que se ha producido una retracción en la producción. Según las percepciones de los expertos, ha habido una disminución de casi la mitad en las tiradas de los medios impresos, lo que ha llevado, lógicamente, a que el posicionamiento de estos medios sea mucho menor en todos los puntos de distribución. Además, ante la desaparición de algunos medios menores, 
se ha producido una considerable disminución de la oferta especializada para los inmigrantes. Para los expertos entrevistados, no sólo ha sido evidente la desaparición de medios, sino que el tiraje de las publicaciones ha reducido considerablemente. Esta coyuntura se ha producido, en su perspectiva, como consecuencia de la retracción de la inversión publicitaria, tanto la proveniente de las empresas grandes como de las medianas y las pequeñas. Ante el retraimiento de la publicidad, las tarifas se han abaratado, ya no solamente en el caso de los medios de comunicación pequeños, sino en los medios españoles que han puesto su incidencia en los nichos publicitarios migrantes. Estas sinergias han provocado un mayor nivel de competitividad de medios "españoles" con medios "inmigrantes".

En el sondeo que aplicamos en el 2007 a los directivos de los medios dirigidos a inmigrantes, se daba cuenta de una alta incidencia de las entidades financieras, bancos y aseguradoras como clientes publicitarios de los medios producidos en Madrid, seguidos por empresas de servicios de telefonía, remesadoras e inmobiliarias, agencias de viajes y aerolíneas (RETIS, 2006). Tres años más tarde, los expertos en "marketing étnico" reconocen la retirada de estos clientes de la cartera manejada en estos días. El inicial entusiasmo del sector publicitario ante un nicho en evidente alza en la primera mitad de la década, ha sobrevenido en un frenazo de los flujos de inversión en los medios dirigidos a inmigrantes. Esta disminución se ha producido no sólo con la publicidad comercial sino con la publicidad institucional, que también se apreciaba considerablemente en los ingresos de los medios producidos principalmente en Madrid y Barcelona pero distribuidos a nivel nacional.

Como apuntábamos antes, la coyuntura de la crisis económica ha sido una variable significativa en la elaboración de este análisis, no sólo en el marco de la elaboración del trabajo de campo, sino en las propias declaraciones de los informantes. Las percepciones sobre el contexto de la crisis económica en general, los efectos en la sociedad española y la incidencia en el nivel de vida en el contexto transnacional de los migrantes latinoamericanos y sus familias, han sido los principales prismas 
desde donde los informantes han venido evaluando sus procesos de consumo cultural, sus relaciones sociales y afectivas dentro y fuera de sus comunidades de pertenencia.

Tanto en los grupos de discusión como en las entrevistas individuales, identificamos algunos elementos de consenso:

a. La reducción de los consumos debido a la crisis. La percepción generalizada de que nos encontramos en un momento crítico de la economía en la que los inmigrantes tienden a reducir los consumos que no consideran vitales para su subsistencia. Por tanto, a lo largo de las declaraciones, encontramos referencias permanentes a estrategias de supervivencia como reducción de consumos en materia de restaurantes, cine y ocio en general. Estos nuevos comportamientos no han sido valorados aún en los sondeos y encuestas de audiencias. Probablemente, aparezcan las variaciones porcentuales en estudios futuros.

b. El factor precio. El valor monetario de los productos culturales y mediáticos. Esta valoración se produce como consecuencia de la primera. En las entrevistas observamos cómo los informantes recalcan el valor de los productos y realizan comparativas con otras ciudades, otros países, o, simplemente con el beneficio de no gastar dinero en determinados productos y servicios.

c. La estimación de la gratuidad. Al amparo de lo anterior, los discursos de los informantes, sobre todo en los que llevan mucho más tiempo de residencia y/o los de mayor edad, tienden a apuntar la gratuidad de los productos y servicios como un valor al alza en la elección de los usos y las prácticas mediáticas y culturales.

d. El factor tiempo como un valor preciado en el intercambio de productos mediáticos y simbólicos. Los inmigrantes latinoamericanos tienden a definir su consumo cultural en términos del tiempo. Estos períodos no invertidos en situaciones de trabajo o de relaciones familiares suelen estar supeditados a una serie de jerarquías en las valoraciones que hacen de los usos de sus cotidianeidades. Como 
consecuencia, nos encontraremos con diversas justificaciones a la escasez de consumos culturales debido a la falta de tiempo.

e. La visión crítica del endogrupo y de otros grupos inmigrantes. Encontramos una constante en el trabajo de campo y es la capacidad de autocrítica sobre el conjunto de «nosotros, los latinoamericanos» 0 «nosotros, los ecuatorianos», o «nosotros, los colombianos», frente al «ellos, los españoles» e incluso «ellos, los murcianos» o «ellos, los madrileños». En estas relaciones pares de semejanza/ antagonía, las prácticas culturales son evaluadas en su carácter colectivo. En este caso, han sido significativas las discrepancias en los grupos de discusión, más evidentes en las fronteras generacionales y de género: los jóvenes y las mujeres de las entrevistas y los grupos de discusión han sido más críticos en estos aspectos.

f. La elevada segmentación de la alta cultura. En los párrafos siguientes analizamos a detalle la valoración crítica de los consumos culturales y mediáticos. Sin embargo, uno de los consensos encontrados es la constatación de que el consumo de alta cultura resulta segmentado y concentrado en los grupos de mayor nivel educativo y/o adquisitivo. En muy escasas ocasiones los informantes han reconocido acudir a conciertos de música clásica, museos o exposiciones.

g. Preeminencia de los consumos mediáticos. Tal como ocurre en el panorama latinoamericano, los inmigrantes entrevistados para este estudio reconocen central el consumo de medios en sus prácticas culturales.

h. Acrecencia del consumo de nuevas tecnologías. Como hemos apuntado en la revisión de los estudios de mercado precedentes, los inmigrantes de esta investigación exploratoria han reconocido el incremento del uso de los teléfonos móviles y el acceso a Internet, especialmente para consultar el correo electrónico, chatear y consultar páginas web.

i. Escasa participación en las actividades culturales. En el análisis detallado de los grupos y las entrevistas describiremos las diferentes 
posiciones sobre este aspecto. Sin embargo, hemos encontrado consenso en los informantes sobre la escasa participación en las actividades culturales y sociales, salvo determinadas excepciones, que detallaremos más adelante.

La complejidad de los procesos de llegada y asentamiento de los inmigrantes internacionales se vislumbra también en las concepciones ante diversos temas que les atañen. En las discusiones de grupo especialmente, pero también en las entrevistas en profundidad, hemos encontrado posicionamientos divergentes u opuestos frente a situaciones comunes. En general, podemos apuntar los siguientes:

a. La incidencia de la variable generacional en las percepciones sobre los procesos de incorporación a la sociedad de destino. Las personas adultas tienden a tener una posición más crítica con su entorno de origen. Mientras que los jóvenes plantean posiciones más críticas con la sociedad de destino. Respecto a los consumos culturales, por ejemplo, los informantes de mayor edad reconocen las ventajas comparativas debido al mejor nivel adquisitivo adquirido en España. Los más jóvenes, recurren a estrategias de defensa ante entornos que interpretan como menos favorables para el consumo. Estas posiciones se evidencian en los grupos de discusión, particularmente, en el caso de Madrid.

b. La variable generacional influye también en las decisiones de consumo y compra. Los informantes mayores tienden a tener una perspectiva más austera frente a los consumos, argumentando la coyuntura de la crisis económica. En sus explicaciones sobre nuevas estrategias de ahorro en los consumos cotidianos, muestran un especial interés en descartar todos aquellos consumos considerados como secundarios. En el caso de los jóvenes, sin embargo, no hemos comprobado posiciones tan austeras respecto a sus prácticas cotidianas.

c. La valoración de la oferta mediática de producción española tampoco ha supuesto un consenso generalizado. Nos hemos encontrado con posiciones divergentes en la evaluación crítica de 
la oferta televisiva. Aunque se tiende a valorar más positivamente la producción de los países de origen, por su cercanía temática y cultural, las críticas a la producción española varían desde la percepción negativa a las copias de programas importados y la calidad informativa, a la percepción positiva de los programas de comedia y documentales. En este sentido hemos identificado algunas diferencias, particularmente en la variable género. Los hombres tienden a ser más críticos con los contenidos informativos. Las mujeres aprecian más las producciones cómicas e infantiles.

d. La asistencia a espectáculos y conciertos se ha descubierto más común en los entrevistados jóvenes que en las personas mayores. Aquéllos reconocen poder salir la mayor parte de los fines de semana, mientras que éstos reconocen promover en mayor medida encuentros en el hogar o en entornos públicos que permitan realizar consumos menos dispendiosos.

e. Las personas mayores tienden a participar más de los eventos culturales. Los jóvenes tienden a confirmar el desconocimiento de este tipo de eventos y, en algunas ocasiones, confirman asistir de manera casual. En donde sí hemos encontrado consenso es en la participación, aunque de manera indirecta en las celebraciones conmemorativas y/o religiosas. Quienes han respondido favorablemente sobre su participación activa en este tipo de actividades han coincidido con ser miembros de agrupaciones folclóricas de música y danza de los países de origen.

\section{Apuntes para la reflexión}

En trabajos recientes hemos venido anotando la importancia de desarrollar estudios de carácter comparado, de perspectiva transnacional y que apunten a comprender los procesos de llegada, asentamiento y acomodo de los grupos migrantes internacionales (RETIS, 2011). Las sinergias económicas acontecidas en la región latinoamericana, Estados Unidos y Europa vienen promoviendo reconfiguraciones de los circuitos migratorios transfronterizos. En nuestro trabajo de campo hemos 
constatado segundos y terceros proyectos migratorios de latinoamericanos provenientes del sur al norte de Europa y hacia Norteamérica. Estos desplazamientos aún en sus estadios recientes hacen preveer reconfiguraciones de las familias transnacionales latinoamericanas. La investigación comparada sobre medios dirigidos a latinoamericanos en ciudades como Los Ángeles, Nueva York, Londres o Madrid nos permite comprender procesos globales, locales e incluso hiperlocales, en el contexto de las dinámicas de producción, distribución y consumo de bienes y servicios. La aproximación cualitativa a las prácticas de consumo cultural de inmigrantes ecuatorianos y colombianos en entornos urbanos y rurales de Madrid y Murcia nos ofrece algunas pistas sobre las que seguir trabajando. Sin duda, es un terreno fértil sobre el que aún nos queda mucho por explorar.

\section{Bibliografía}

ASOCIACIÓN PARA LA INVESTIGACIÓN DE LA COMUNICACIÓN. Los inmigrantes en el EGM. Línea Abierta, n. 41, p. 2-3, 2004.

. Los inmigrantes y su consumo de medios. Línea Abierta, n. 45, p. 7-8, 2005.

BAÑÓN, A. Discurso e inmigración. Propuestas para el análisis de un debate social. Múrcia: Universidad de Murcia, 2002.

BERMÚDEZ TORRES, A. Political Transnationalism, Gender, and Peace-building Among Colombian Immigrants in the UK and Spain. 2008. 272f. Tese (doutorado em Geografia) - Queen Mary University of London, Londres, 2008.

CALLEJO, J. Consumo cultural, televisión y espacio local: una aproximación empírica. Signo y pensamiento, n. 47, p. 105-120, 2005.

CANCLINI, N. G. Culturas híbridas. Estrategias para entrar y salir de la modernidad. México: Grijalbo, 1989.

. Latinoamericanos buscando un lugar en este siglo. Buenos Aires: Paidós, 2002.

Los estudios culturales de los ochenta a los noventa: perspectivas antropológicas y sociológicas. In: (Org.). Cultura y pospolítica. El debate sobre la modernidad en América Latina. México: Consejo Nacional para la Cultura y las Artes, 1995. p. 17-38.

CASILDA, R. La década dorada. Economía e inversiones españolas en América Latina 1990-2000. Madri: Ediciones de la Universidad de Alcalá, 2002. 
CHAVERO, H.; GARCÍA-MUÑOZ, N. Los hábitos del consumo televisivo de una comunidad extranjera: el caso de estudiantes latinoamericanos en Barcelona. Zer, n. 19, p. 191-204, 2005.

COLECTIVO IOÉ. Inmigración y consumo en España. Exploración inicial de las necesidades, los hábitos de consumo y la capacidad emprendedora de los inmigrantes del Tercer mundo residentes en España. Madri: C.A.V.E., 2001.

.; FERNÁNDEZ, M. Encuesta Nacional de Inmigrantes 2007: El mercado de trabajo y las redes sociales de los inmigrantes. Madri: Ministerio de Trabajo y Asuntos Sociales, 2008.

DIAZ NOSTY, B. Los medios de comunicación en la experiencia migratoria latinoamericana. Madri: Fundación Telefónica, 2007a.

Tendencias 07. Medios de comunicación en el escenario iberoamericano. Madri: Fundación Telefónica, 2007b.

GABARDO, J.; SANTIAGO, F. Los inmigrantes residentes en España y su medición en el EGM. In: SEMINARIO DE MEDIOS AEDEMO, 11., 2008, Málaga. Anais... Málaga, nov. 2008. p. 1-38.

GONZÁLEZ, M. Consumos e influencia mediática en el transcurso de una experiencia migratoria. El caso de cinco colectivos identificados en la provincia de Málaga. 2005. 326f. Tese (doutorado em Ciências da Comunicação) - Universidad de Málaga, Málaga, 2005.

GUARNIZO, L. Londres latina. La presencia colombiana en la capital británica. México: Porrúa, 2008.

HUERTAS, A. El consumo cultural de los latinoamericanos en Cataluña: integración ciudadana y transnacionalismo. In: CONGRESO DE LA ASOCIACIÓN DE ESTUDIOS LATINOAMERICANOS, 2009, Rio de Janeiro. Anais... Rio de Janeiro, 2009.

HUERTAS, A. et al. El consumo mediático de los jóvenes y su influencia en los procesos de sociabilidad entre inmigrantes y autóctonos. In: CONGRESO INTERNACIONAL DE LA ASOCIACIÓN ESPAÑOLA DE INVESTIGACIÓN EN COMUNICACIÓN, 2010, Málaga. Anais... Málaga, 2010.

IZQUIERDO, A.; LÓPEZ, D.; MARTÍNEZ, R. Los preferidos del siglo XXI: la inmigración latinoamericana en España. In: GARCÍA, F.; LÓPEZ, C. (Orgs.). La inmigración en España: contextos y alternativas. Granada: Laboratorio de Estudios Interculturales, 2002. p. 237-289.

MARTÍN BARBERO, J. Recepción de medios y consumo cultural: travesías. In: SUNKEL, G. (Org.). El consumo cultural en América Latina. Bogotá: Colección Agenda Iberoamericana, Convenio Andrés Bello, 2006. p. 47-71.

PRICE, M.; BENTON-SHORT, L. Counting Cities Across the Globe. Report by the Migration Information Institute. Washington: MIS, 2007.

RETIS, J. Diásporas contemporáneas y medios étnicos en ciudades globales: Madrid, Los Ángeles, Londres. Research Project. California State University, 2010.

El discurso público sobre la inmigración latinoamericana en España. Análisis de la construcción de las imágenes de los inmigrantes latinoamericanos en la prensa de 
referencia. 2006. 489f. Tese (doutorado em América Latina Contemporânea) - Instituto Universitario de Investigación Ortega y Gasset, Universidad Complutense de Madrid, Madri, 2006.

Espacios mediáticos de la inmigración en Madrid: Génesis y evolución. Madri: Observatorio de las Migraciones y la Convivencia Intercultural de la Ciudad de Madrid, 2008.

. Estudio exploratorio sobre el consumo cultural de los inmigrantes latinoamericanos en España: el contexto transnacional de las prácticas culturales. Madri: Fundación Alternativas, 2011.

Inmigración y medios de comunicación: aproximaciones y propuestas para las buenas prácticas periodísticas. Madri: Ministerio de Asuntos Sociales de España, 2008. .; GALÁN, E. Qué nos siguen contando sobre la inmigración en España: Análisis comparado de los recientes discursos en la ficción televisiva y la prensa de referencia". In: CONGRESO INTERNACIONAL AE-IC, II, 2010, Málaga. Anais... Málaga, 2010. RETIS, J.; GARCÍA, P. Imágenes mediáticas de los jóvenes latinoamericanos en la prensa europea: la construcción mediática de los pánicos morales. In: CONGRESO INTERNACIONAL DE AMERICANISTAS, 53., 2009, México. Anais... México, 2009.

RETIS, J.; SIERRA, F. Rethinking Latin American Communicology in the Age of Nomad Culture: Transnational Consumption and Cultural Hybridizations. Londres: WPCC, 2011.

SANTAMARINA, C. Consumo y ocio de los inmigrantes latinoamericanos en España. Un acercamiento desde la perspectiva cualitativa. Madri: Ministerio de Trabajo y Asuntos Sociales, 2007.

SASSEN, S. The Global City: New York, London, Tokyo. Nova York: Princeton University Press, 2001.

VAA. Informe encuesta nacional de inmigrantes (ENI-2007). Madri: Instituto Nacional de Estadística: Ministerio de Trabajo e Inmigración, 2008.

\section{Sobre la autora}

Professora Associada do Departamento de Jornalismo na California State University Northridge, EUA. Graduada em Comunicação Social pela Universidade de Lima, Mestre em Estudos Latino-americanos na Universidade Autônoma do México e Doutora em América Latina Contemporânea na Universidade de Madrid.

Fecha de envío: 05/12/2017

Fecha de aceptación: 15/12/2017 